\title{
Construcción del concepto audiencia como objeto de estudio en la modernidad contemporánea. Una aproximación teórica, epistemológica y metodológica con foco en la TV pública
}

institucional.us.es/ambitos/

$24 / 2 / 2016$

\section{José Enrique Fernández}

Facultad de Información y Comunicación. Instituto de Comunicación. Universidad de la República. Montevideo (Uruguay)

jose.fernandez@fic.edu.uy

\section{Ana Marta Martínez}

Facultad de Información y Comunicación. Instituto de Comunicación. Universidad de la República. Montevideo (Uruguay)

anamarta.martinez@fic.edu.uy

English Version: The concept of audience development as the under study in contemporary times. A theoretical, epistemological and methodological view focused in public tv broadcasting

\section{Resumen}

Presentamos una discusión sobre la construcción de las categorías audiencias y recepción como objeto de estudio, con foco en la Tv pública. El contexto está definido teóricamente como modernidad liquida o reflexiva, con un proceso de crecimiento en niveles de abstracción e individualización en detrimento de los actores y las instituciones sociales. El artículo incluye una discusión teórica y epistemológica, desarrollando un diseño metodológico concreto para investigaciones de audiencias desde un enfoque de métodos combinados, en el entendido que es una herramienta ajustada a objetos de estudio complejos que

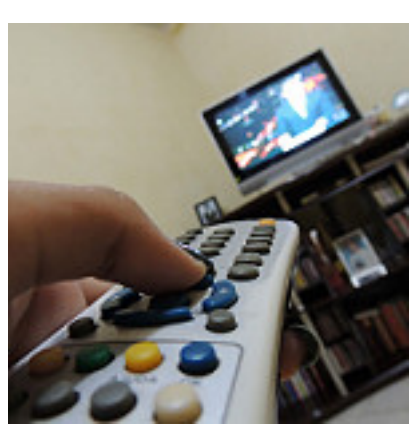
abarcan múltiples planos de la realidad.

\section{Palabras clave}

Audiencias, televisión pública, modernidad reflexiva, multi-métodos.

\begin{abstract}
We present a discussion about the construction of the categories audiences and reception as a object of study, focused on the public Tv. The context is defined theoretically as liquid or reflexive modernity, whit a process of growth in levels of abstraction and individualization to the detriment of actors and social institutions. The article includes a theoretical and epistemological discussion, developing a specific methodological design to audience

research from a focus of combined methods, on the understanding that is an appropriate tool set to complex objects of study spanning multiple planes of reality.
\end{abstract}

Keywords Audiences, public television, reflexive modernity, multi-methods research.

\section{INTRODUCCIÓN}

Como investigadores en el campo de la Comunicación nos enfrentamos al desafío de producir conocimiento original sobre audiencias, teniendo en cuenta las especificidades que asume este objeto de estudio en el marco de la modernidad contemporánea, con sus implicancias teóricas y metodológicas. A esto se suma la necesidad que manifiestan los actores responsables de la 
dirección de la Tv pública en Uruguay de contar con un nuevo tipo de conocimiento que les permita programar e interactuar con las audiencias desde una lógica de generación de valor público, en un nuevo escenario en que, la Ley de Servicios Audiovisuales prevé el incremento de canales de televisión (Tv) públicos, así como transformaciones en características y cobertura que conlleva la digitalización, en un tiempo de dispositivos "multipantallas". Omar Rincón sintetiza algunos de los desafíos relevantes para orientar el mencionado proceso.

"Lo más urgente es que los medios de la gente pasen de la obsesión por los contenidos a las exploraciones estéticas y narrativas. El asunto es cómo le damos forma a nuestra experiencia desde nuestros gustos, códigos culturales y referentes estéticos. Por eso, los medios de la gente deben producir nuevos formatos de narración de sujeto y de colectivo, hacer posible que haya muchas más voces, rostros, ideas y estilos presentes y existiendo en la comunicación ciudadana" (Rincón, 2011: 43-50).

En este sentido, presentamos a continuación una discusión teórica y epistemológica sobre la construcción del objeto de estudio "audiencias" en el marco de la modernidad contemporánea, y una propuesta metodológica basada en un diseño combinado o multi-métodos que se desarrolla como opción para superar las limitaciones que nos plantean las estrategias cuantitativas y cualitativas habituales en esta área del conocimiento.

\section{LA DISCUSIÓN TEÓRICA}

Aunque los estudios culturales se inician en la década del 60, la noción de audiencias en plural sustituyendo a la de público es subrayada por David Morley en los 80 . Su tesis fundamental es que los receptores imprimen su sentido, al sentido que proponen los medios. La producción, el producto y la audiencia no deben pensarse separados y formula categorías ideológicas como ejes básicos de la relación de las audiencias con la comunicación de masas. Da relevancia al origen y el contexto social de las audiencias para la comprensión de la recepción, lo que denomina marcos culturales y posición social. Dada la importancia que otorga al contexto social y cultural, a partir de su obra, que marcó a una generación de teóricos críticos, fermentan en América Latina distintas orientaciones: Consumo Cultural: Néstor García Canclini, Enfoque integral de la audiencia: Guillermo Orozco, Uso social de los medios: Jesús Martín Barbero, Frentes culturales: Jorge González y Recepción activa: Valerio Fuenzalida.

Para Morley (1996), el sentido último de la recepción no es satisfacer necesidades personales, sino procesar contradicciones estructurales mediante negociaciones entre la posición social y el marco cultural que no son coincidentes. Las clases sociales instauran sistemas de sentido que dan decodificaciones diferenciadas. Introduce el concepto de subcultura como sistemas de sentido y modos de expresión acumulados mediante los cuales los grupos que se encuentran en posiciones estructurales subordinadas intentan negociar con el sistema de sentido dominante u oponerse a él (sistema de valores dominante, sistema de valores subordinado, sistema de valores radical). De aquí se desprende una lectura preferencial que acepta el sentido del mensaje hegemónico, una lectura negociada donde se decodifica de acuerdo a la posición social del receptor y una lectura de oposición donde el decodificador aporta un marco de referencia distinto e impone una interpretación alternativa. Mauro Wolf sintetiza lo sustantivo de la diferencia entre público y audiencias enfatizando en que lejos de ser pasivas; las audiencias están determinadas por: "el interés por adquirir información, la exposición selectiva provocada por las actitudes existentes, la interpretación selectiva, la memorización selectiva" (Wolf, 1990: 21-153).

Denis Mc Quail aporta una formulación más gráfica y conciliadora. "En la práctica, lo que existe es un continuo en uno de cuyos extremos se encuentra la masa y en el otro el pequeño grupo homogéneo, situándose las audiencias reales en posiciones intermedias" (McQuail, 1991).

Más allá de los llamados estudios cuantitativos de medición de audiencia, que son referencia para el mercado, entre la oferta televisiva global (pública y privada; abierta o para abonados; por Internet) y la población en general, existe una caja negra de difícil acceso, en donde no es posible atribuir impactos concretos a nivel de relaciones causales entre los productos televisivos y los cambios socioculturales de las audiencias. Gustavo Hernández fundamenta sobre la complejidad metodológica que implica el abordaje de la referida "caja negra": 
"la unidad de análisis del paradigma cualitativo es el sujeto en tanto constructor e intérprete de discursos polisémicos. Es el sujeto en toda su dimensión psicosocial, cultural e histórica, por demás compleja, heterogénea e imprevisible. En la investigación en comunicación este sujeto equivale a la audiencia de la comunicación de masas, entendida en líneas generales, como aquella comunidad que interpreta, sobre la base de su repertorio de mediaciones, la construcción ideológica de los medios masivos" (Hernández, 2005: 156).

La producción de bienes privados está sobre-determinada en primera instancia por la generación de rentabilidad. De ahí la necesidad de medir audiencia en forma cuantitativa. Más allá del valor público que se puede generar en una televisora privada, este nunca será el objetivo último de la actividad. En la Tv pública, hay que pensar en términos de producción de valor público como objetivo estratégico. Puede haber muchas formas de delimitar o conceptualizar el término, pero en grandes líneas podemos hablar de producción de bienestar. Si bien tanto el Estado, el Mercado y también la Comunidad pueden y deberían producir valor público, un aspecto que identifica a los gobiernos progresistas es el rol que detenta el Estado en este proceso. Por lo tanto, un canal público en este contexto, no puede considerarse aislado de un proceso social y político que involucra al resto de la sociedad.

Investigar sobre la relación actual y futura de la Tv pública con su audiencia real y potencial, implica desentrañar aspectos cruciales de esa caja negra que media entre el canal, el mensaje emitido, y las audiencias. El equilibrio entre los contenidos que el Estado quiere emitir dentro de una lógica de generación de valor público, y las formas en que las audiencias integran a la televisión en su vida cotidiana es clave para llegar al mayor público posible con productos culturales que no estén sobre-determinados por la lógica de la rentabilidad.

Esta lógica además ya no es tan diáfana como lo era en la denominada modernidad sólida o clásica. Mientras en aquella la rentabilidad y la economía en general presuponían el concepto de escasez, hoy a partir de los cambios radicales que ha introducido Internet en todos los órdenes de la relación del hombre con el mundo, no es la escasez sino la abundancia (medido en visitas y productos indirectos o externalidades) la que otorga valor. Jeremy Rifkin es uno de los que se refiere a la sociedad contemporánea como "era del acceso":

"En nuestro tiempo se están empezando a desintegrar los fundamentos de la vida moderna. Las instituciones, que en cierto momento estimularon a los hombres a entrar en conflictos ideológicos, revoluciones y guerras se ven lentamente enterradas por el despertar de una nueva constelación de realidades económicas que están contribuyendo a que la sociedad reconsidere los tipos de vínculos y fronteras que definirán las relaciones humanas en el siglo venidero. En esta nueva era, los mercados van dejando sitio a las redes y acceso constituye cada vez más a la propiedad. (...) Los conceptos, las ideas, las imágenes - no las cosas - son los auténticos artículos con valor en la nueva economía" (Rifkin, 2000: 14-15).

La red de redes, además implica la emergencia de un nuevo actor. El término "prosumidor" combina al otrora usuario con el productor y aunque se populariza recientemente, M. McLuhan y A. Toffler ya lo advierten desde los setentas. Para Guillermo Orozco, hay un proceso en el que el concepto "recepción" pasa a ser relegado por el de "capacidad de emisión" en la definición de la categoría "audiencia". (Orozco, 2009: 287-296). Comentando el planteo de Orozco, Ana R. Mantecón discute los efectos de los cambios:

“... las audiencias se vuelven usuarias, productoras y emisoras, en la medida en que la interactividad que permiten las nuevas pantallas trasciende la mera interacción simbólica con ellas, para situar a las audiencias como creadoras de sus propios referentes, no sólo como re-creadoras simbólicas de significados o interpretaciones de los referentes producidos y emitidos por otros desde esas pantallas" (Mantecón, 2010: 3742).

Lo anterior lleva a considerar el desafío de superar el nivel descriptivo de los estudios convencionales de rating, y avanzar en un esfuerzo comprensivo que permita reconstruir los procesos individuales y colectivos que se generan en la recepción. Para esto tenemos que definir dos tipos de aspectos claves para orientar los estudios de audiencias.

A nivel teórico, por un lado nos orientamos al inicio por las categorías planteadas desde el enfoque de la recepción activa, desarrollado entre otros por Valerio Fuenzalida, quien conceptualiza a la recepción como un 
espacio - tiempo psicológico de descanso definido por cuatro factores mediadores: la Tv tiene un lenguaje lúdico afectivo y dramático; se distingue por la recepción en el hogar; responde a la expectativa de la audiencia entre los diversos nichos tecnológicos (Tv abierta o paga) y, existe una imagen corporativa del canal. (Fuenzalida, 2009: 11-29). Este lenguaje lúdico-afectivo es la propia identidad de la televisión. El sentimiento y expectativa situacional de descanso, relajación y entretención es la relación más básica que la audiencia televisiva entabla con la TV (diferente a la de otros espacios de aprendizaje y capacitación). Gustavo León Duarte comentando a Valerio Fuenzalida afirma:

"la influencia grupal es sumamente importante en la construcción del sentido que las personas le confieren al mensaje. En este sentido, la familia, la mediación televisiva y la interacción con grupos organizados de todo tipo, ejercen una influencia decisiva en los hábitos y preferencias de información, en la recepción del mensaje y en la elaboración de las significaciones socioculturales del individuo. Para el investigador chileno, lo que muestran en definitiva los estudios de recepción es que el receptor socio-cultural y el contexto de la recepción televisiva son constituyentes activos del proceso de Comunicación. No son "recipientes o variables intervinientes" (Duarte, 2002: 19-47).

Frente al significado intencional querido por el emisor, frente al significado inmanente al texto detectado por el análisis semiótico, también existe lo que llama "el significado concreto y existencial, es decir lo constituido por el receptor en su interacción con el mensaje y el con su emisor” (Duarte, 2002: 19-47).

Para Fuenzalida lo que existe es un contrato previo que el espectador ya firmó. "El lenguaje audiovisual es polisémico y glamoroso por lo que afecta más a la fantasía y a la afectividad que a la racionalidad humana, se rige más por la retórica que por la lógica formal". (Fuenzalida, 2006: 5).

La recepción mayoritariamente ocurre en el hogar/familia. Por lo tanto el abordaje se debe hacer en las condiciones contextuales de audiencia, a partir de estrategias comprensivas que, con base en técnicas cualitativas, registren las conductas cotidianas más la verbalización de la significación que tienen estas conductas para los actores. Esta metodología permite comprender la tradicional contradicción entre opiniones verbalizadas y conductas manifiestas. A diferencia de otros consumos culturales, la TV revela una recepción cotidianizada, ruidosa y conversada distinta a la obtenida por técnicas de laboratorio (grupos focales) donde se suprimen las interferencias contextuales. Más allá de identificar opiniones y percepciones significativas en relación a los productos televisivos, el desafío será avanzar en cuanto a las dinámicas de decodificación e interpretación en el consumo mediático hogareño. Es importante en este punto agregar que Fuenzalida describía un consumo hogareño donde la televisión detentaba una posición central que agrupaba la familia, ante esto es menester hacer dos puntualizaciones, si bien el lenguaje lúdico afectivo y la expectativa de entretención parecen sobrevivir el desarrollo por un lado de los dispositivos multipantalla y por otro la proliferación de nuevos modelos de familia influyen en aquella recepción bulliciosa y colectiva que retrató Fuenzalida. Es probable que la recepción raramente sea colectiva y de serlo posiblemente no se desarrolle en un ámbito central. En nuestros estudios empíricos exploratorios hemos podido observar algunas estrategias de resistencia hacia este poder seductor de la tv, desalojándola ex profeso de los lugares colectivos de reunión de la casa.

La generación de hábitos y preferencias está influida por los grupos de pertenencia del individuo que son diversos e interactúan con espacios sociales que suponen interacciones sujetas a múltiples racionalidades. El estudio de estos fenómenos encuentra una extensa fundamentación en el campo de la teoría de los "efectos cognitivos de los medios" que a su vez se enmarca en la sociología del conocimiento y sirve de cimiento a nuestra estrategia metodológica. Se postula la centralidad que adquieren los procesos simbólicos y comunicativos imbricados en la socialización, es decir la acción permanente, acumulativa y autorreferencial de los medios y el conjunto de destrezas que adquieren los sujetos para presentarse ante los otros. El presupuesto aquí es el de la dependencia entre los procesos tecnológicos de mediación simbólica y la construcción de la imagen pública en una sociedad. Tomando el concepto de frame desarrollado, entre otros, por Erving Goffman, podemos pensar los media como algo parecido a una gran malla sintáctica o un macro frame que establece una continuidad de entendimiento entre el sistema otorgador de sentido de los media y las imágenes del conocimiento compartidas públicamente. Pero también al convocar a Goffman, es ineludible hablar del orden de la interacción, la definición de situación, y una de sus nociones más vigentes: la ambivalencia. Ulrrich Beck 
subraya lo crucial de este concepto, especialmente en torno a los desafíos que la ambivalencia plantea a la metodología sociológica:

"Puede mostrarse que no solo las formas y medidas organizativas, sino también los principios y categorías éticos y legales, como la responsabilidad y la culpa (por ejemplo, el principio de que pague quien contamina), así como los procedimientos políticos de decisión (como el principio de mayoría) no son adecuados para comprender o legitimar este retorno de la incertidumbre e incontrolabilidad. De modo análogo, es cierto que las categorías y métodos de la ciencia social fracasan frente a la vastedad y ambivalencia de los hechos que deben abordar y abarcar" (Beck; Lash; Giddens, 1997: 24).

Beck señala que es posible poner en relación mutua las subracionalidades, solo aparentemente autorreferenciales y aplicar a éstas un experimento mental metarracional, y advierte:

“... no en el sentido del "todo vale", sino en el de una refundamentación centrada, una creación o, más prudentemente, una corrección de racionalidades sistémicas que se han hecho obsoletas e históricamente irracionales. Por ejemplo, ¿no requiere un tipo diferente el reconocimiento de la ambivalencia que nos impone la civilización de riesgo, es decir, una nueva clase de racionalidad científica (lógica de investigación, reglas de procedimiento, teoría y metodología experimental y un replanteamiento del procedimiento subsistémico de revisión inter pares de resultados)? (...) En otras palabras, la modernización reflexiva significa también y esencialmente una "reforma de la racionalidad" que haga justicia al a priori histórico de la ambivalencia en una modernidad que está aboliendo sus propias categorías" (Beck; Lash; Giddens, 1997: 50).

Debemos detenernos brevemente para zurcir un puente en vistas al desarrollo teórico futuro, tanto de este estudio como de cualquier otro que se proponga iluminar cualquier forma de consumo cultural. Por un lado volver a escuchar a Rifkin:

"De manera creciente compramos el tiempo de otros, su afecto y cuidado, su simpatía y atención. Compramos la diversión y la información culta, la elegancia y el aspectos, y en medio de otras muchas cosas - incluso el mismo discurrir del tiempo ya es una forma de control y fichaje - . La vida resulta cada vez más mercantilizada y desaparecen las diferencias entre comunicación, comunión y comercio". (Rifkin, 2000: 20).

Este economista plantea que en el marco de la economía hipercapitalista, impregnada en las relaciones de acceso, todo nuestro tiempo se mercantiliza. Según Wolfgang Giegerich a partir del desarrollo de internet ya se ha materializado la abstracción y complejidad que se fue forjando durante la modernidad clásica. Hoy en la civilización tecnológica (caracterización influida por la obra de Hans Jonas), la tecnociencia tienen un motor propio autopropulsado y existe una inmediata y global aplicación de las innovaciones lo cual hace que Internet ya haya cambiado totalmente la forma general de la relación del ser con el mundo.

Si Bauman hablaba de la importancia en esta modernidad del concepto de ambivalencia (Bauman, 2005), concepto que a su vez tomaba de Goffman quien sostiene en su obra "Estigma: La identidad deteriorada", que la noción de normalidad es un tema de relaciones no de atributos (expectativas virtuales acerca de tipos ideales), una parte del intangible social se desnuda en toda su fragilidad. Hoy en este mundo tanto más abstracto y complejo que el de la modernidad anterior, las formas de entretenernos e informarnos mediante ese lenguaje emocional, que según Wolfgang Giegerich adquiere características autistas (emociones autistas que nos encierran en nosotros mismos e intermedian en cualquier otro tipo de relación). Este extremo que alcanza el consumo de contenidos audiovisuales, y que mediante los dispositivos multipantalla se vuelve ubicuo, debe ser una categoría de las más importantes a estudiar.

Se impone si escuchamos a los teóricos citados y si queremos hacer justicia al fenómeno de la Tv no dejar fuera del objeto de estudio las nuevas formas de mirar Tv a través de internet. Si queremos hablar de contenidos no podemos soslayar la importancia cada vez menor de los contenidos en relación con la apariencia, el diseño y lo que Giegerich denomina proceso de estetización.

Para concluir esta breve aproximación teórica se impone subrayar otra clara constatación: estamos en deuda en lo que concierne a la caja de herramientas, es decir al arsenal teórico metodológico con el contamos en vistas a la complejidad y abstracción que esta nueva realidad nos plantea. 
Beck justamente en el ensayo citado antes habla de conceptos zombis, que al tiempo que mueren resucitan pero no con vida y explica que el concepto de muerte plantea dificultades a los científicos sociales:

"El colapso del bloque oriental, sin embargo, ha demostrado que puede haber algo así como un infarto gubernamental. Quien excluya el concepto de "muerte institucional" olvida con qué nos enfrentamos por doquier en estos días de cambio radical: instituciones- que llevan clínicamente muertas largo tiempo pero que son incapaces de morir. Como ejemplos, uno podría citar los partidos de clase sin clase, los ejércitos sin enemigos, los aparatos gubernamentales que en tantos casos pretenden iniciar y mantener situaciones que ocurrirán o se mantendrán de todos modos" (Beck; Lash; Giddens, 1997: 59).

A lo largo del ensayo Beck sostiene la tesis de que las instituciones también mueren víctimas de su propio éxito. En esta modernidad tan controversialmente llamada (tardo, posmo, líquida, reflexiva, de riesgo, entre otras), está sucediendo un proceso de desvinculación y revinculación a nuevas formas de vida de la sociedad industrial en sustitución de las antiguas, en las que los individuos deben producir, representar y combinar por sí mismos sus propias biografías que denomina individualización. Este proceso no se da por casualidad "ni voluntariamente, ni a través de diversos tipos de condiciones históricas, sino de una vez y en las condiciones generales del estado de bienestar en la sociedad industrial avanzada, tal como ha evolucionado a partir de los años sesenta en numerosos países occidentales” (Beck; Lash; Giddens, 1997: 28).

Este proceso, entendemos, se ha denominado también como el fin del individuo, pero lo que se presenta aún más removedor de Beck es el llamado urgente a pensar nuevas categorías. Dice que antes, pensando en la modernidad anterior, las categorías se pensaban como muñecas rusas, una dentro de otra, la clase presupone la familia nuclear y las clases se concebían como la suma de las situaciones de las familias nucleares.

"Estas categorías no están siendo reemplazadas por un vacío (ese es precisamente el objetivo de la mayoría de las refutaciones de la teoría de la individualización), sino por una nueva forma de conducir y organizar la vida, ya no obligatoria y "vinculado" (Giddens) a modelos tradicionales, sino basada en el Estado de bienestar. Este último, sin embargo, presupone al individuo como actor, diseñador, malabarista y director de escena de su propia biografía, identidad, redes sociales, compromisos y convicciones. Expresándolo llanamente "individualización" significa la desintegración de las certezas de la sociedad industrial y la compulsión de encontrar y buscar nuevas certezas para uno mismo y para quienes carecen de ellas. Pero también significa nuevas interdependencias, incluso interdependencias globales. La individualización y la globalización son, de hecho, dos caras del mismo proceso de modernización reflexiva" (Beck; Lash; Giddens, 1997: 29).

Romper con las categorías tipo muñecas rusas y saldar esta deuda teórico metodológica es obviamente una empresa que deberá convocar recursos de primera línea y esfuerzo sostenido de los mejores investigadores a nivel mundial y que sin duda tal concreción no podrá emerger hasta tanto las propias nuevas instituciones globales que se correspondan con el nuevo lugar de poder nazcan, sean paridas, no sin el esfuerzo, "parirás con dolor" que todo nacimiento implica ruptura, creación y destrucción. En esta muy acotada investigación lo que apuntamos es la inadecuación y la urgente necesidad de repensar categorías a la hora de hablar de audiencia, recepción y tv, sobre todo observando la emergencia de la red de redes y las radicales trasformaciones que en todos los órdenes de la vida trae consigo y, sobre todo, que llegó para quedarse. Nadie sabe cómo será el mundo del mañana, así afirmó Bauman en From Privacity to Publicity en Junio de 2015 es irresponsable hacer predicciones, pero seguramente sea un mundo cada vez más y más conectado. Si queremos hacer justicia y darle la mejor oportunidad posible al estudio de la realidad, lo primero es reconocer esta tendencia y apartarnos de esa actitud intelectual que, Giegerich retrata, juega al "hacer como si nada". No, no podemos seguir haciendo como si nada pues darle la espalda a esta tendencia compromete seriamente cualquier estudio sobre la Tv en general y la Tv pública en particular.

\section{DESARROLLO METODOLÓGICO}

\subsection{Estrategia}

A nivel metodológico, nos planteamos la siguiente pregunta: ¿cuáles son las estrategias metodológicas y 
técnicas más apropiadas para abordar un objeto de estudio que ha cambiado radicalmente en los últimos años?

Para ajustar el análisis a la complejidad que plantea la modernidad contemporánea necesitamos desarrollar un abordaje flexible que tenga en cuenta la acumulación cualitativa y cuantitativa pero que no sea la sumatoria simple de ambas. Queremos generar un proceso en el que desde una lectura etnográfica se construya una tipología cualitativa, cuya distribución pueda ser analizada a nivel de población con métodos cuantitativos. De hecho, existe desde mediados del siglo XX una tradición creciente de enfoques integradores, a saber, "Ecléctico", "Pragmático", "Mixto". Esta opción está discutida en profundidad por María Celina Chavarría cuando sustenta que referirse a un paradigma cualitativo, cuantitativo o mixto produce una dicotomía simplificadora que fragmenta. Las distinciones pertinentes son epistemológicas y a ese nivel corresponde la discusión, no entre cuanti, cuali o mixto e indica:

“... no es pertinente religar aquello que nunca ha estado desligado. (...) A la luz de la discusión anterior, resulta confusa la terminología de enfoque ecléctico (Hammersley, 1996) o mixto (e.g., Guba y Lincoln desde el constructivismo; Gelo et al., 2008; Johnson \& Omuwegbuzie, 2004 desde el pragmatismo). Supone, de nuevo, arbitrariamente escindir, para luego postular reglas para combinar, como reflejarían los 40 diferentes diseños para combinar métodos (Cf. Gelo et al., 2008). Es necesario concienciar que cualquier intento de síntesis o de regulación proviene de un lugar, explícito o implícito, de alguna tradición paradigmática. Desde una perspectiva compleja, se sugiere como epistemológicamente más apropiado referirnos a enfoques multi-método, si se quiere (con la ventaja de conservar el MMR por multi-methods research), pues toda aproximación metódica tiene componentes cualitativos y conlleva escogencias sopesadas" (Chavarría González, 2011: 1-35).

Asumiendo la tensión epistemológica que esto genera, la propuesta de desarrollo metodológico se inscribe dentro de los enfoques de métodos combinados o multi - métodos que en este caso implica una configuración de estrategias y técnicas organizadas secuencialmente.

\subsection{Fase 1. Estudio etnográfico}

Lo más importante que se destaca en la literatura actual sobre el tema es que la recepción ocurre en el hogar/familia. Esta es la primera precisión metodológica, el fenómeno se debe estudiar reproduciendo las condiciones contextuales de audiencia, a partir de la etnografía: la observación de conductas cotidianas más la verbalización de la significación. En este sentido proponemos realizar entrevistas colectivas a familias en donde, dentro del hogar, se reconstruyan rutinas y situaciones de audiencia.

Las entrevistas tienen tres etapas.

Una primera similar a un grupo de discusión, en la que se plantean las preguntas vinculadas a nuestras categorías de investigación.

En el segundo bloque, se le solicita a cada integrante presente que nos reproduzca una situación en la que ve televisión solo, y al grupo una situación en la que ven televisión acompañados. Se observan acciones individuales, grupales, y condiciones de contexto.

En el tercer bloque, se exhibe un demo de un programa a estrenar de TV pública (o dos, uno de consumo general y otro para un público objetivo específico) y se analizan las respuestas.

La guía de entrevista y observación tiene que estar basada en las categorías teóricas del enfoque "recepción activa". Es importante que este estudio se complemente con la medición de algunas variables demográficas y socio-económicas que permitan contextualizar a la familia, y otras variables acerca de la infraestructura tecnológica disponible para acceder a la oferta audiovisual existente.

\subsection{Fase 2. Construcción de tipología}

Además de un informe que interprete en profundidad el fenómeno de recepción activa observado, y su relación con la programación e imagen actual y futura de la Tv, se propone generar un indicador sintético cualitativo, que permita manejar una tipología de hogares-individuos (audiencias individuales y grupales). Esta etapa es básicamente un proceso de producción de teoría y articula la propuesta multi-métodos conectando una fase 
donde predomina el enfoque cualitativo con otra donde predomina el cuantitativo.

\subsection{Fase 3. Estudio extensivo de población}

A partir de los resultados del estudio etnográfico, es necesario seleccionar un grupo de variables, con preferencia las relacionadas con la Tipología de Audiencia, para relevarlas en una muestra de población. Con los insumos generados en las dos fases anteriores se propone construir escalas de Likert (Likert, 1932), considerando que es una herramienta de probada eficiencia y una buena síntesis metodológica de abordajes cualitativos y cualitativos.

\section{REFERENCIAS BIBLIOGRÁFICAS}

BAUMAN, Z. (2005): Modernidad y Ambivalencia. México-Buenos Aires: Anthropos.

- (2015): From Privacity to Publicity [en línea]. <https://youtu.be/CGk-iaTr9hk>

BECK, U.; LASH, S. ; GIDDENS, A. (1997): Modernización reflexiva: política, tradición y estética en el orden social moderno. Buenos Aires: Alianza Editorial.

CHAVARRÍA GONZÁLEZ, M. C. (2011): La dicotomía cuantitativo/cualitativo, falsos dilemas en la investigación social. Actualidades en psicología, vol 25, n 112, pp. 1-35.

DUARTE, G. A. L. (2002): Teorías e Investigación de la Comunicación. Ámbitos, nº 7-8, pp. 19-47.

FUENZALIDA, V. (2006): Estudios de audiencia y recepción en Chile. Diálogos de la Comunicación, n 73, pp. 5.

FUENZALIDA, V. (2009): Nuevas tendencias de la televisión pública en América Latina. En: Televisión pública: experiencias de Alemania y Latinoamérica. Buenos Aires: Fundación Konrad Adenauer, pp. 11-29.

GIEGERICH, W. (2007): La función de la televisión y el problema del alma En: Technology and the Soul. From the Nuclear Bomb to the World Wide Web. Collected English Papers, vol. 2, Spring Journals.

- (2007):La www desde el punto de vista de la vida lógica del alma En: Technology and the Soul. From the Nuclear Bomb to the World Wide Web. Collected English Papers, vol. 2, Spring Journals.

- (1998): The solul's logical life.Nueva York - Berlín: Peter Lang.

GOFFMAN, E. (1970): Estigma. La identidad deteriorada. Buenos Aires: Amorrortu.

HERNÁNDEZ, G. (2005): ¿Y dónde está la audiencia?. En: Televisión pan nuestro de cada día.. s.l.:Alfa, pp. 156.

LIKERT, R. (1932): A technique for the measurement of attitudes. s.l.:Archives of psychology.

MANTECÓN, A. R. (2010): Del público al prosumidor. Nuevos retos para los estudios de consumo cultural. Entretextos, vol. 6, pp. 37-42.

MCQUAIL, D. (1991): Introducción a la teoría de la comunicación de Masas. Barcelona: Paidós.

MORLEY, D. (1996): Televisión, audiencias y estudios culturales. Buenos Aires: Amorrortu.

OROZCO, G. (2009): Entre pantallas. Nuevos escenarios y roles comunicativos de sus audiencias-usuarios. En: Pensar lo contemporáneo: de la cultura situada a la convergencia tecnológica.. Barcelona: Anthropos/ UAMIztapalapa, pp. 287-296.

RIFKIN, J. (2000): La era del acceso. La revolución de la nueva economía. Barcelona - Buenos Aires - México: 
Paidós.

RINCÓN, O. (2011): Nuevas narrativas televisivas: relajar, entretener, contar, ciudadanizar, experimentar. Comunicar, vol. XVIII, n 36 , pp. 43-50.

WOLF, M. (1990): Contextos y paradigmas en la investigación sobre los media. En: La investigación de la comunicación de masas. Buenos Aires: Ediciones Paidós Ibérica Barcelona y Editorial Paidós, SAICF, pp. 21 153.

\section{BREVE SEMBLANZA DE LOS AUTORES}

José Enrique Fernández. Uruguayo. Sociólogo. Master en Trabajo Social. Profesor de la Facultad de Información y Comunicación. Coordinador del Departamento de Epistemología, Metodología e Historia del Instituto de Información y coordinador de la Sección Académica Metodología del Instituto de Comunicación. Investigador Senior en Políticas Sociales, Infancia, Información y Comunicación. Consultor en Sistemas Estratégicos de Información.

Ana Marta Martínez. Uruguaya-mexicana. Dra. en Sociología y Master en Comunicación por la Universidad Nacional Autónoma de México. Licenciada en Comunicación. Profesora en los institutos de Comunicación e Información de la Facultad de Información y Comunicación de la Universidad de la República. Dicta cursos de Maestría y Doctorado en la Universidad de la Empresa. Líneas de investigación: transmedia, metodología, modernidad, minorías y ética.

Ámbitos. Revista Internacional de Comunicación, n.31, edición de invierno, 2016.

Recibido: 26/03/2015

Aprobado: 25/04/2015 